\title{
Ofatumumab - a valid treatment option for chronic lymphocytic leukemia patients
}

\author{
This article was published in the following Dove Press journal: \\ Therapeutics and Clinical Risk Management \\ 20 July 2017 \\ Number of times this article has been viewed
}

\author{
Salma M AIDallal \\ Haematology Laboratory, Amiri \\ Hospital, Kuwait City, Kuwait
}

Correspondence: Salma M AIDallal Haematology Laboratory, 25, Amiri Hospital, Kuwait City, Kuwait, 150300 Tel +9659098 1981

Email dr.s.aldallal@outlook.com

\begin{abstract}
Ofatumumab Arzerra ${ }^{\circledR}$ is a human monoclonal antibody, which induces killing of a panel of tumor B-cell lines and primary tumor cells by the activation of in vitro complementdependent cytotoxicity and antibody-dependent, cell-mediated cytotoxicity. The humanized anti-CD20 monoclonal antibody has been approved by the US Food and Drug Administration for the treatment of chronic lymphocytic leukemia patients. This article summarizes this antibody's therapeutic effect on chronic lymphocytic leukemia.
\end{abstract}

Keywords: ofatumumab, cell-mediated cytotoxicity, chronic lymphocytic leukemia

\section{Introduction}

Chronic lymphocytic leukemia (CLL) is a clonal disorder of B-cells. But before we delve into the details of CLL, it is imperative to have an understanding of the typology of leukemia. It is classified into acute or chronic on the basis of maturity of abnormal cells. If they are immature, they are more like stem cells and if they happen to be mature, they resemble normal white blood cells. In the latter, the cells can mature only partly and as such do not score high on the immunological scale. As a consequence, they cannot counter infection the way white blood cells do. Leukemia cells, however, live longer than white blood cells and take a long time before they actually start creating problems. The disease is revealed by the increasing accumulation of these cells, mainly in the blood, bone marrow and lymphatic tissues. ${ }^{1}$ The most important causes of death in patients with CLL are complications relating to pancytopenia, infection, and hemorrhage. ${ }^{2}$ CLL is one of the most widespread types of leukemia among adults in the West. It accounts for more than a quarter $(25 \%-30 \%)$ of all leukemia types. ${ }^{3}$ The average age of diagnosis of CLL is about 70 years and it occurs more frequently in males than in females, with a ratio of $2: 1 .^{4}$

Although patients might present with lymphadenopathy (swollen lymph node), show symptoms of anemia or infection, and experience night sweats, weight loss or tiredness, the submission stated that $50 \%-80 \%$ of CLL cases were asymptomatic and diagnosed incidentally at a routine blood count (CBC). ${ }^{5}$ That is the principal reason as to why it is considered to have a highly inconsistent clinical course. The diagnosis of CLL is conducted with the help of $\mathrm{CBC}$, blood smear, and immunophenotyping of circulating B-cells. ${ }^{6}$

There are two staging systems for CLL: the Rai system and the Binet system, both of which employ physical examination and CBC. The former differentiates three prognostic groups with different clinical outcomes: ${ }^{3,6}$ 1) Stage 0, lymphocytosis; 2) Stage I-II, lymphoadenopathy, organomegaly; 3) Stage III-IV, anemia, thrombocytopenia. 
The Binet staging system, however, is subdivided into three stages with patients being classified on the basis of number of involved sites as well as the incidence of anemia. The occurrence of anemia is evaluated in accordance with certain standards, such as hemoglobin $<10 \mathrm{~g} / \mathrm{dL}$ and/or thrombocytopenia with platelets $<100.000 / \mu \mathrm{L}: 3,7$

1. Stage A: fewer than three involved lymphoid sites

2. Stage B: three or more involved lymphoid sites

3. Stage C: presence of anemia and/or thrombocytopenia.

There are of course patients who are classified as being in the early stage of CLL and yet undergo rapid progression of the disease. As a result, additional prognostic factors have come into play. These factors are the presence of certain serum markers (beta-2 microglobulin, thymidine-kinase), genetic markers (IGHV mutational status), cytogenetic abnormalities (including ZAP-70 expression, CD38 expression and 11q, $13 \mathrm{q}$ and $17 \mathrm{p}$ deletions), and other genetic lesions (mutations in SF3B1, NOTCH, and BIRK3 gene)., ${ }^{3,7}$

\section{Ofatumumab in CLL}

The use of human monoclonal antibodies for treating CLL marked an era of significant change with regard to the treatment of malignant and progressive diseases, with the focus shifting from chemotherapy toward targeted therapy. The drugs used in targeted therapy fight leukemia by arresting the growth and spread of the cells responsible for the anomaly as opposed to chemotherapy, wherein the drugs flow along the bloodstream to reach nearly every part of the body. Chemotherapy harms healthy cells in the process. Targeted therapy boasts of fewer side effects naturally. The first stage in this process of change involved the initiation of monoclonal antibodies, particularly anti-CD20 antibodies such as obinutuzumab, rituximab and ofatumumab, in combination with immunochemotherapy. Of late, small molecular inhibitors have appeared which target the B-cell receptor signaling pathways, immunomodulation (lenalidomide, immunomodulatory drugs [IMiDs]), and BCL-2 (ABT-199). ${ }^{10}$ These inhibitors function at important positions on the pathways to attain a greater measure and/or longer duration of therapeutic activity targeted at such diseases. ${ }^{11}$

Ofatumumab (Arzerra $\left.{ }^{\circledR}\right)$ is an immunoglobulin G1 (IgG1) kappa human monoclonal antibody with a molecular weight of $\sim 149 \mathrm{kDa}$. It is produced in recombinant murine cell lines (NS0) with the help of standard mammalian cell cultivation and purification technologies. ${ }^{12,13}$ The antibody particularly binds to CD20 on the surface of B-cells. Thus, it activates antibody-dependent cell-mediated cytotoxicity and complement-dependent cell lysis of CD20 overexpressing B-cells. CD20, which is a nonglycosylated cell surface phosphoprotein, acts as a calcium iron channel. It is only expressed on B-cells during most stages of B-cell development. ${ }^{14}$ Ofatumumab, administered intravenously, is available in single-use vials containing either $100 \mathrm{mg} / 5 \mathrm{~mL}$ or 1,000 mg/50 mL. ${ }^{15}$ The US Food and Drug Administration (FDA $)^{15}$ dosage recommendation for extended treatment is as follows: $300 \mathrm{mg}$ on day 1, followed by $1,000 \mathrm{mg}$ a week later and subsequently $1,000 \mathrm{mg}$ after a period of 7 weeks. From thereon, a dose of $1,000 \mathrm{mg}$ should be continued every 8 weeks up to a maximum duration of 2 years.

Treatment options for CLL depend on factors such as disease stage, age of the patient, and the presence of cytogenetic lesions or concomitant disease. Patients diagnosed at an early stage should only be observed. ${ }^{3}$ On the other hand, patients who have reached advanced Rai or Binet stages or are afflicted with the active, symptomatic disease need therapy. Physically fit patients are treated with chemoimmunotherapy with cyclophospamide, fludarabine, and rituximab. However, physically impaired patients should be treated with an anti-CD20 antibody in combination with mild chemotherapy in the form of chlorambucil. ${ }^{6}$

At a relapse, disease progresses after a period of 6 months or after either partial or complete remission, the initial treatment could be repeated if the interval, which is devoid of treatment, exceeds 2 or 3 years. ${ }^{16}$ If relapse occurs earlier, the treatment should be adjusted with the help of alternate agents, such as alemtuzumab, bendamustine (plus rituximab), ibrutinib, ofatumumab, and idelalisib. ${ }^{17}$ A combination of rituximab and idelalisib or ibrutinib could be used to treat patients with a del (17p) or TP53 mutation. Patients who are refractory to repeated chemotherapies or immunotherapies, or relapsing patients with TP53 mutations or del (17p) could consider allogenic stem cell transplantation. ${ }^{6}$

A Phase III COMPLEMENT 2 study conducted showed that the treatment of CLL patients with ofatumumab in combination with fludarabine and cyclophosphamide $(n=183)$ improved progression-free survival by $54 \%$ and improved overall response rate ( $84 \%$ vs $68 \%$, respectively) as compared to those receiving fludarabine and cyclophosphamide alone. The median overall survival was 56.4 and 45.8 months for combination therapy and individual therapy, respectively $(P=0.1410){ }^{18}$

\section{Summary}

CLL is a condition affecting the elderly as it particularly impacts those who have crossed the age of 50 years. In it significant amounts of blood stem cells turn into abnormal white blood cells, which do not serve the function that healthy ones 
do. In other words, they are not able to adequately counter infections. Their number, too, keeps increasing. As a result, there is less room for normal white blood cells, platelets, and red blood cells. This in turn leads to complications in the form of infections, easy bleeding and anemia. But, despite decades of clinical trials, it remains incurable. Some patients survive for long periods, while others die rapidly in spite of intensive therapy. Since most CLL patients express CD20 on their malignant cells, anti-CD20 monoclonal antibody agents have been incorporated into treatment regimens, including ofatumumab. Ofatumumab was approved by the FDA on the basis of a prolonged trial. Those who took ofatumumab exhibited close to double the rate of survival, without progression of the disease, in comparison with those who did not take it. Ofatumumab (Arzerra) was approved by the FDA in January 2016 for extensive treatment of CLL patients. ${ }^{15}$ The treatment showed major activity and a favorable safety profile, thereby providing meaningful clinical improvements in CLL patients. The results of the studies conducted were encouraging and further investigation is necessary. ${ }^{17}$

\section{Acknowledgment}

The author is thankful to www.manuscriptedit.com for providing English language editing and proofreading services for this manuscript.

\section{Disclosure}

The author reports no conflict of interest in this work.

\section{References}

1. Dighiero G, Hamblin TJ. Chronic lymphocytic leukaemia. Lancet. 2008; 371(9617):1017-1029.

2. National Cancer Institute [homepage on the Internet]. Chronic lymphocytic leukemia treatment-for health professionals (PDQ). [updated January 20,2017; cited 2016]. Available from: http://www.cancer.gov/types/ leukemia/hp/cll-treatment-pdq\#cit/section_1.19. Accessed November 1, 2016.

3. Rai R, Stilgenbauer S. Epidemiology and clinical manifestation of chronic lymphocytic leukemia. [updated 2017, cited 2016]. Available from: http:// www.uptodate.com/contents/clinical-presentation-pathologic-featuresdiagnosis-and-differential-diagnosis-of-chronic-lymphocytic-leukemia. Accessed January 11, 2017.
4. Yu EM, Kittai A, Tabbara IA. Chronic lymphocytic leukemia: current concepts. Anticancer Res. 2015;35(10):5149-5165.

5. Yee KW, O'Brien SM. Chronic lymphocytic leukemia: diagnosis and treatment. Mayo Clin Proc. 2006;81(8):1105-1129.

6. Hallek M. Chronic lymphocytic leukemia: 2015 update on diagnosis, risk stratification, and treatment. Am J Hematol. 2015;90(5):446-460.

7. NCCN Guidelines Version 1. National Comprehensive Cancer Network (NCCN). [updated 2017, cited 2016]. Available from: http:// www.nccn.org/professionals/physician_gls/pdf/nhl.pdf. Accessed January 11, 2017.

8. Gale RP, Rai KR. Chronic lymphocytic leukemia: recent progress and future directions. J Natl Cancer Inst. 1988;80(1):65-66.

9. Binet JL, Auquier A, Dighiero G, et al. A new prognostic classification of chronic lymphocytic leukemia derived from a multivariate survival analysis. Cancer. 1981;48(1):198-206.

10. Sandhu S, Mulligan SP. Ofatumumab and its role as immunotherapy in chronic lymphocytic leukemia. Haematologica. 2015;100(4):411-414.

11. O'Shea JJ, Laurence A, McInnes IB. Back to the future: oral targeted therapy for RA and other autoimmune diseases. Nat Rev Rheumatol. 2013; 9(3):173-182.

12. European Medicine Agency. Arzerra: EPAR-product Information. [cited January 29, 2015]. Available from: http://www.ema.europa eu/docs/en_GB/document_library/EPAR_Product_Information/ human/0,01,131/WC50,00,93,091.pdf. Accessed January 12, 2017.

13. Lemery SJ, Zhang J, Rothmann MD, et al. U.S. Food and drug administration approval: ofatumumab for the treatment of patients with chronic lymphocytic leukemia refractory to fludarabine and alemtuzumab. Clin Cancer Res. 2010;16(17):4331-4338.

14. National Cancer Institute. NCI Drug Dictionary - Ofatumumab. [cited January 29, 2015]. Available from: http://www.cancer.gov/ publications/dictionaries/cancer-drug?cdrid $=5,30,015$. Accessed January 12, 2017.

15. Novartis Pharmaceuticals Corporation. Drugs@FDA: FDA Approved Drug Products. [cited 2016]. U.S. Food and Drug Administration. Available from: http://www.accessdata.fda.gov/drugsatfda_docs/ label/2016/1,25,326s062lbl.pdf. Accessed January 12, 2017.

16. Hallek M, Cheson BD, Catovsky D, et al. Guidelines for the diagnosis and treatment of chronic lymphocytic leukemia: a report from the international workshop on chronic lymphocytic leukenia updating the national cancer working group 1996 guidelines. Blood. 2008;111(12): $5446-5456$.

17. Grossmann N, Baumann M. Horizon Scanning in Oncology: Ofatumumab (Arzerra) as maintenance therapy in patients with relapsed chronic lymphocytic leukaemia (CLL). [cited 2016]. Ludwig Boltzmann Gesellschaft GmbH. Available from: http://eprints.hta.lbg.ac.at/884/1/ DSD_HSO_Nr.10.pdf. Accessed January 12, 2017.

18. Novartis International AG. Novartis drug Arzerra ${ }^{\circledR}$ improved median progression-free survival by $54 \%$ in patients with relapsed chronic lymphocytic leukemia. [cited 2015]. Available from: https://markets. $\mathrm{ft} . \mathrm{com} /$ data/announce/full? dockey=1330-477844en-4OOTQKA 21L3OAFDM41RMPK59DH. Accessed June 20, 2017.
Therapeutics and Clinical Risk Management

\section{Publish your work in this journal}

Therapeutics and Clinical Risk Management is an international, peerreviewed journal of clinical therapeutics and risk management, focusing on concise rapid reporting of clinical studies in all therapeutic areas, outcomes, safety, and programs for the effective, safe, and sustained use of medicines. This journal is indexed on PubMed Central, CAS,

\section{Dovepress}

EMBase, Scopus and the Elsevier Bibliographic databases. The manuscript management system is completely online and includes a very quick and fair peer-review system, which is all easy to use. Visit $\mathrm{http}: / / \mathrm{ww}$.dovepress.com/testimonials.php to read real quotes from published authors. 